ISSN No. 2454 - 1427

CDE

October 2017

\title{
STIGMA OR RED TAPE? ROADBLOCKS IN THE USE OF AFFIRMATIVE ACTION
}

\author{
Ashwini Deshpande \\ Email: ashwini@econdse.org \\ Department of Economics \\ Delhi School of Economics
}

Working Paper No. 280

http://www.cdedse.org/pdf/work280.pdf

\section{CENTRE FOR DEVELOPMENT ECONOMICS}

DELHI SCHOOL OF ECONOMICS

DELHI 110007 


\title{
Stigma or Red Tape? Roadblocks in the Use of Affirmative Action*
}

\author{
Ashwini Deshpande ${ }^{\dagger}$
}

October 12, 2017

\begin{abstract}
Affirmative action in India is largely caste-based and takes the form of quotas or reservations of seats in public institutions of higher education, government jobs and elected positions. Using a mixed methods research design, this paper examines whether and to what extent, additional stigmatization adversely affects the use of reservations for higher education or jobs. The quantitative analysis is based on a primary survey conducted by the author in the city of Delhi in 2014-15. The empirical analysis focuses on differences in perception of additional stigma of affirmative action between two groups: individuals from the Scheduled Castes (SCs) or Dalits, who belong to castes that are already highly stigmatized, to those from Other Backward Classes (OBCs) who belong to castes and communities that might be low-ranked, but not necessarily stigmatized. The results indicate that a greater proportion of SCs use reservations at least once as compared to OBCs, and a higher score in Class XII (the school leaving examination) increases the probability that individuals will avail of reservations. As a reason behind the non-use of reservations, between 9 and $16 \%$ of the non-users cite stigma as a reason. Overall, bureaucratic red tape and lack of information constitute much more substantial reasons for the non-use of reservations compared to stigma. Non-use of quotas due to possible additional stigmatization is a bigger factor for OBCs compared to SCs. The paper also contains qualitative accounts based on in-depth interviews of 61 individuals, who got into college on reserved seats, and successfully completed their chosen course of study. These detailed accounts give insights into institutional barriers that pose challenges to the full assimilation of affirmative action beneficiaries, as well as highlight the multiple layers of disadvantage that they battle with.
\end{abstract}

JEL: J71, J78, Z13

Keywords: Affirmative Action, Caste, India, Stigma, Discrimination

${ }^{*}$ The analysis in this paper was possible due to funding from the European Union Seventh Framework Programme (FP7/2007-2013) under grant agreement $\mathrm{n}^{\circ}$ 290752. The quantitative survey would not have been possible without my Ph.D. student, Apoorva Gupta's initiative and efforts, and her excellent leadership and management of the survey. I would like to thank her and the entire team of research assistants for their sterling fieldwork. Thanks are also due to Yatish Arya, Mrinalini Jha and S. Prasham for help with the qualitative interviews, and to Lakshita Jain for her help with transcribing interviews and organizing the background data for the qualitative section. Abhinash Bora, Rajesh Ramachandran and participants at the conference on "Prejudice, Stigma and Discrimination: Combatting Exclusions Through Policy and Law", University of Chicago, Delhi Centre, gave extremely useful comments. I take responsibility for all remaining errors and omissions.

${ }^{\dagger}$ Department of Economics, Delhi School of Economics, University of Delhi, Delhi 110 007. India. Email: ashwini@econdse.org 


\section{Introduction}

Critics of affirmative action (AA) have for long argued that the policy is unfair to non-beneficiaries because it denies entry to eligible and meritorious candidates for prized positions. ${ }^{1}$ This is now complemented by a view that AA is also harmful to the beneficiaries because of two reasons. One, it sets beneficiaries up for failure due to potential "mismatch" because they are granted entry into programs that they might not be equipped to handle. Two, it doubly stigmatizes them: in addition to the stigma on account of their identity, it stamps them with a stigma of incompetence. Thus, the argument goes, AA ends up doing more harm than good.

The question of the added stigma of AA is hard to gauge, as low-ranked groups are often negatively stereotyped for a multiplicity of reasons, including being considered incompetent. Thus, if they are stigmatized in institutional contexts where they have gained entry through AA, it is not immediately apparent to what extent AA might be responsible for the incremental increase in stigma, over and above what they would have experienced on account of their "stigmatized ethnic identity" (Berreman, 1971). Typically, because AA is seen as a policy that grants entry to presumably less 'meritorious' ${ }^{2}$ individuals from low-ranked groups in place of more 'meritorious' individuals from high-ranked groups, it is widely resented, both by those who are denied entry, as well as by the general public who might not be personally directly affected by AA. Thus, AA beneficiaries might often face hostility and discrimination inside institutions where they gain access. However, would they be less stigmatized had they not availed of AA to gain entry into a given institution, and had instead chosen another trajectory of study or work? This is a difficult counterfactual question, not easy to estimate precisely.

There are three important dimensions of stigma of AA that can be explored more directly. First, do beneficiaries internalize the stigma they encounter in institutional settings where they have gained entry through AA? Second, more importantly from a policy perspective, does the fear of stigmatization affect the uptake of AA? Third, what is the experience of assimilation and integration for those individuals who have availed of AA or reservations to gain entry? This latter dimension should be explored for all AA beneficiaries, regardless of the degree of success they achieve in the programme, but especially given the focus on mismatch and anecdotal accounts of beneficiaries dropping out, it is especially important to record the experiences of those beneficiaries who successfully graduate.

The analytical apparatus of social psychology is particularly useful to probe the first question of internalization and its possible effect on beneficiary performance. In a companion paper (Deshpande, 2016), I have attempted to explore the issue of 'externalization', i.e., beneficiaries are stigmatized by their peers as incompetent, i.e. stigma exists, versus 'internalization', i.e., beneficiaries internalize the low valuation that their peers place upon them, lowering their own self-worth. While earlier literature treated the existence of stigma as synonymous with its internalisation by the stigmatized individuals, the more recent literature, particularly the Stereotype Content Model (Fiske

\footnotetext{
${ }^{1}$ See references in Leslie et al, 2014.

${ }^{2}$ The notion of using examination scores as an indicator of merit is problematic, as I discuss in Deshpande, 2013. However, examination scores are widely viewed as indicators of merit, and given that AA beneficiaries enter with lower scores, they are commonly viewed as less meritorious
} 
et al, 2002), questions the almost automatic presumption of internalisation, and emphasises the distinction between the existence of stigma (externalization), and its internalization.

In this paper, my attempt is to investigate the second and third questions: do individuals who are eligible for affirmative action lower their uptake because of fear of added stigmatization? Also, what were the actual experiences of individuals as they entered institutions marked as AA beneficiaries? Given the multi-faceted nature of these questions, I believe that a mixed-methods research methodology is most useful to get a glimpse into the nuances that shape these somewhat intractable issues. The assessment of uptake is hampered by lack of suitable data, as existing data sets do not allow us to estimate how uptake is affected by other factors, of which fear of stigmatization might be one. More broadly, data on the use of reservations are very hard come by, even simply the on the total numbers of people using reservations. ${ }^{3}$ I conducted a primary survey on a larger question of 'education and social mobility' in Delhi during 2014-15. Since I was curious about the role of stigma in the uptake of AA, I included a module in the survey in order to assess precisely the uptake of quotas by those who are eligible, and what factors account for non-use of AA. The main result from this data is that the bulk of non-use of quotas is not due to fear of added stigmatization. The overwhelming reasons for non-use are bureaucratic hurdles and red tape, which can be interpreted as institutional apathy or road blocks preventing the successful implementation of the policy. Comparing individuals from the Scheduled Castes (SCs) or Dalits to those from Other Backward Classes (OBCs) I find that non-use of quotas due to possible additional stigmatization is a smaller factor for SCs, who belong to castes that are already highly stigmatized, than for OBCs, who belong to castes and communities that might be low-ranked, but not necessarily stigmatized.

Additionally, with a team of students, in a separate small survey, we identified 'reserved category' individuals (i.e. affirmative action beneficiaries) who had successfully graduated. We conducted semi-structured interviews that collected basic background information from everyone, but also included an open-ended component for personal narratives. The idea was to hear voices from the ground, especially from those who had successfully graduated. Needless to add, this component is exploratory and preliminary; the idea is to pave the way for further research along this direction.

The rest of the paper is organised as follows. Section 2 briefly describes the basic features of AA in India along with a brief review of the literature. Section 3 presents the results of the quantitative estimation based on data from the 'Education and Social Mobility' survey. Section 4 contains a preliminary analysis of the qualitative interviews. Section 5 contains a discussion of the results, along with concluding comments.

\section{Review of Related Literature}

The affirmative action policy in India is primarily caste-based, ${ }^{4}$ and consists of reserved seats or quotas in government run educational institutions, government jobs and at all levels of government.

\footnotetext{
${ }^{3}$ I am engaged in a project, along with Marc Galanter, to collect data on the actual use of quotas.

${ }^{4}$ Additionally, 33 percent seats are reserved for women in elected positions in rural and urban local bodies.
} 
22.5 percent seats are reserved for Scheduled Castes (SCs) and Scheduled Tribes (STs), which are administrative umbrella categories that list the designated castes (jatis) and tribes. This is a modified version of a policy of reserving seats for untouchable castes ${ }^{5}$ that started in the second decade of the 20th century in certain parts of British India and princely states. ${ }^{6}$ Additionally, 27 percent seats are reserved for 'Other Backward Classes' (OBCs) ${ }^{7}$ at the central level, in jobs since 1993, and in educational institutions since 2008. While SC and ST are administrative categories, I would also use Dalit (meaning the oppressed, a term of pride used for self-identification for castes that were considered untouchable such that any contact with them was considered polluting) and Adivasi (meaning literally, the original inhabitants) for the caste and tribal categories respectively.

There is a small body of literature on the 'mismatch hypothesis' in the Indian context, which finds little or no evidence of mismatch (Bertrand et al, 2010; Bagde et al 2016). There is now growing literature on the question of the added stigma of affirmative action in the context of the United States (see studies in Leslie et al 2014; Krishnamurthy and Edlin, 2014). In India, this literature is in its infancy, and there are only a handful of works on this subject. Gudavarthy (2012) and Gille (2013) examine this explicitly, and various papers in Guru (2009) discuss stigma related to reservations as parts of larger arguments. Gudavarthy focuses on the OBC 'politics of recognition', related to their demand for reservations, and how this might alter the terms of the discussion around 'democracy, equality and dignity', which is dominated by 'received . . . dominant . . . upper caste discourse' (2012: 55, 62). The argument is that the recent demand for quotas by higher-ranked OBCs might help de-stigmatize reservations, as it would no longer be the preserve of the traditionally stigmatized castes, that are low-ranked and considered incompetent. Gille (2013) investigates the use of quotas and finds that OBCs with greater land ownership (richer, higher status) tend not to use reservations, but that the use of reservations by SCs is not related to their economic status.

In a companion paper (Deshpande, 2016), based on concepts and theories from social psychology, I investigate, through a primary survey in colleges and departments of University of Delhi, whether Dalit and Adivasi students internalize the stigma of incompetence that their peers mark them with. I find that the stigma is real, i.e. upper caste peers believe that 'quota students' are incompetent and do not deserve to be in the institution. This does lead to an increase in pressure due to greater 'academic performance burden' for beneficiaries, but they do not internalize the stigma, i.e. they do not consider themselves less capable than their peers. However, the question of internalization is not easy to settle; Hoff and Pandey's (2006) analysis suggests that stereotype threat, or invoking a stigmatized identity, might shift the performance of stigmatized individuals in the direction of the stereotype (i.e. downwards). Whether this happens due to deep-seated internalisation or not is difficult to gauge.

While the body of literature on the particular stigma of affirmative action is small, there is a

\footnotetext{
${ }^{5}$ These were castes so low in the hierarchy that they were not even fit to be assigned a varna status (the avaranas, or the one without a varna).

${ }^{6}$ I have discussed various aspects of the policy in detail elsewhere (Deshpande, 2013).

${ }^{7}$ For details on the OBC category, as well as their relative placement in the caste hierarchy, see Deshpande and Ramachandran, 2016. It should be noted that while OBC reservation at the central level is 27 percent, states have had different quotas for certain non-SC-ST castes and communities since Independence.
} 
very large and rich body of historical writings on the caste system, pioneered by seminal analyses of thinkers such as Jotirao Phule, B.R. Ambedkar and Periyar E.V. Ramasamy, who articulated insightful and searing critiques of the caste hierarchy and convincingly demonstrated how it is discriminatory, exploitative and oppressive towards historically untouchable jatis associated with menial, polluting and hence stigmatizing tasks. While untouchability has been legally abolished in independent India, and is punishable by law, overt and covert instances of untouchability continue (Shah et al, 2006; Navsarjan, 2010; Thorat and Joshi, 2015). Dalits, thus, battle a 'stigmatized ethnic identity' regardless of whether they use reservations. Use of reservations could add an extra dimension to the stigma, and simply confirm upper caste prejudice that Dalits cannot make it without the crutch of affirmative action.

\section{Does Fear of Stigmatization Affect Uptake of Quotas?}

This section examines the central question of this paper, viz., whether there are any differences in the use of quotas between SC-STs (already highly stigmatized) and OBCs (lower ranked, but not necessarily stigmatized) that could be associated with the perception of stigma. No dataset in the public domain explores this issue. Gille (2013) uses the Additional Rural Income Survey and Rural Economic and Demographic Survey (ARIS-REDS) data, which asks respondents the following question: "Have you or any member of your family taken advantage of provisions under reservations to seek admission in educational institution in 2005-06?" However, this data set does not have information on whether any individual actually went to a higher educational institution, where they might have needed to use reservations. Thus, the data are highly inadequate to investigate the issue of stigma, which could potentially arise when eligible individuals, who could have used reservations, chose not to do so. Gille (2013) interprets the entire non-use of quotas as arising because of stigma, because of not being able to distinguishing between those who did not use it out of choice (i.e. did not use it when they could have), and those who did not pursue higher education, and therefore, the question of using or not using quotas never arose for them. Also, for those who could have used reservations but did not, there could be other reasons for not using reservations, for instance, bureaucratic difficulties, or red tape. However, the ARIS-REDS data does not allow the investigation of any of those reasons. Finally, inadequate as it is, in the ARIS-REDS survey, this question is asked only about the use of reservations in education, not employment. Thus, even if the question were properly framed, it would capture only one dimension of quota use. This lacuna is important because it would be rare to find individuals who would refuse the possibility of a secure government job due to fear of stigmatization, especially if they are already stigmatized due to their caste status. Note that this is a survey conducted only in rural areas where the proportion of quota users is lower as opportunities for higher education and government jobs (where quotas are applicable) are far lower than in urban areas. Thus, overall, this data set is not suitable to capture either the use of quotas, or the reasons behind (non)use. 


\subsection{Data and Methodology}

\subsubsection{Data and Summary Statistics}

Results in this section are based on one module of a retrospective primary survey that I conducted for another project on 'Education and Social Mobility'. As a part of the research design, 1049 young men who finished high school in 2003 from government schools in the city of Delhi were sampled in 2014-15. Thus, these men had already been out of high school for 11-12 years, and the survey gathered detailed information about their educational and occupational trajectories during that period. The sample consisted of one gender and was drawn from the same academic cohort from state-run high schools of relatively similar quality. Thus, the starting position of these men as they embarked on their post-high-school lives was expected to be relatively homogeneous.

I designed one module in this survey to gather information about the use of reservations - who used it and who did not, despite belonging to caste groups that were eligible for quotas. Further, if they did not use reservations, the survey asked them what reasons might account for the non-use. To the best of my knowledge, this is the only large-scale quantitative data set that enables a precise assessment of reasons for non-use of quotas by those who are eligible. In addition to data on the respondents' educational and occupational trajectories, the data set has detailed information on the socio-economic characteristics of their families: parents, siblings, and close relatives as well as friends. Among other variables, I also have information on the ownership of 14 consumer durables per household. I have combined this data into an "asset index", using the methodology of "principal components analysis', and based on the values of the index, divided the sample into bottom 40 percent (asset class 1), middle 40 percent (asset class 2) and top 20 percent (asset class 3). This is a rough, and somewhat arbitrary, division of the respondents into 'poor', 'middle-class', and 'rich'. Note that since the sample was drawn from those who studied in government-run schools, it excluded the actual rich section of the population that sends their children to private schools.

Table 1: Summary Statistics SCST

\begin{tabular}{lccccc}
\hline \hline \multicolumn{1}{c}{ Variable } & Mean & Std. Dev. & Min. & Max. & N \\
\hline age & 28.838 & 1.517 & 25 & 34 & 229 \\
xii_score & 54.327 & 9.74 & 33 & 88 & 229 \\
eduyrs & 14.952 & 1.755 & 12 & 21 & 229 \\
assetclass & 1.592 & 0.65 & 1 & 3 & 213 \\
fatheduyrs & 8.825 & 5.102 & 0 & 20 & 229 \\
motheduyrs & 3.206 & 4.047 & 0 & 12 & 228 \\
\hline
\end{tabular}

Tables 1 and 2 show descriptive statistics for the two caste groups that are eligible for AA. We see that by design, the average age of the two groups is almost the same. Statistically speaking, the differences between the two groups are significant only for Class XII score and father's years of education, such that OBCs have higher averages compared to SC-STs. In all other indicators, the differences are not statistically significant. ${ }^{8}$

\footnotetext{
${ }^{8}$ There were only 2 ST individuals in this survey, so those have been clubbed with the SCs.
} 
Table 2: Summary Statistics OBC

\begin{tabular}{lccccc}
\hline \hline \multicolumn{1}{c}{ Variable } & Mean & Std. Dev. & Min. & Max. & N \\
\hline age & 28.53 & 1.428 & 25 & 35 & 181 \\
xii_score & 56.04 & 9.309 & 38 & 80 & 179 \\
eduyrs & 15.133 & 1.733 & 12 & 21 & 181 \\
assetclass & 1.661 & 0.685 & 1 & 3 & 165 \\
fatheduyrs & 9.803 & 4.389 & 0 & 18 & 178 \\
motheduyrs & 3.893 & 4.751 & 0 & 17 & 178 \\
\hline
\end{tabular}

\subsubsection{Methodology}

The first empirical estimation consists of identifying factors that account for the use of reservations. The dependent variable is the outcome variable (called 'quotause') based on the answer to the question "did you use quotas for education or a job or both"? This is a binary variable, which takes the value 1 if the respondent used reservations at least once, and zero if the respondent never availed of reservations. I have also estimated this separately for education and job quotas, but the sample size for the latter is very small as only $9 \%$ of the total sample, and $13 \%$ of those eligible work in government jobs. The probability of reservation use is estimated through a logistic regression, explained below.

Let the binary response variable be

$$
Y= \begin{cases}1, & \text { if used reservations at least once } \\ 0, & \text { if never used reservations }\end{cases}
$$

Let $X=X_{1}+X_{2}+\ldots+X_{k}$ be the set of explanatory variables.

For individual $i$,

$$
\begin{gathered}
\pi_{i}=\operatorname{Pr}\left(Y_{i}=1 \mid X_{i}=x_{i}\right)=\frac{\exp \left(x_{i}^{\prime} \beta\right)}{1+\exp \left(x_{i}^{\prime} \beta\right)} \\
\operatorname{logit}\left(\pi_{i}\right)=\frac{\pi_{i}}{1-\pi_{i}} \\
=\beta_{0}+\beta_{1} x_{i 1}+\beta_{2} x_{i 2}+\ldots+\beta_{k} x_{i k}
\end{gathered}
$$

Explanatory variables used in this regression are: whether the individual is SC or OBC; his assetclass (as a proxy for family background), and Class XII score, which is also strongly influenced by family background characteristics, such as father's education (for a discussion of the latter, see Deshpande, 2017). 
The second estimation analyzes reasons for not using quotas, which we can analyse as outcomes, using the multinomial logit framework.

Consider the outcomes $1,2,3 \ldots m$ recorded in $Y$, and the explanatory variables $X$ as above. In our case, $m=6$. These outcomes are unordered; the numbers $1,2,3 \ldots$ are not indicative of any order of importance of the outcome (reason for not using quotas). Now, Equation (2) gets estimated for each outcome separately, and the probabilities are relative to a base outcome, which I have chosen as "there was no occasion to use quotas" (i.e. the respondent did not study in a setting, or apply for a job where quotas were applicable).

\section{$3.2 \quad$ Results}

\subsubsection{Use of Reservations}

Out of the total sample of 1049 men, 396 individuals (38 per cent) were eligible for AA: 228 from the SC-ST category and 168 from the OBC category. Eligibility is defined in the following way: these men belonged to beneficiary groups and had the minimum qualifications needed to take advantage of job or education quotas, or both (Class X for jobs, Class XII for higher education). Of these, 114 (27 per cent of the eligibles) used reservations in education or jobs, or both.

Table 3: Quota Use by Eligible

\begin{tabular}{|c|c|c|c|}
\hline \multicolumn{4}{|c|}{ Part A: Quota Use } \\
\hline & SCST & $\mathrm{OBC}$ & Total \\
\hline Used quota & 44.3 & 7.74 & 28.79 \\
\hline Did not use & 55.7 & 92.26 & 71.21 \\
\hline Total & 100 & 100 & 100 \\
\hline \multicolumn{4}{|c|}{ Part B: Edu or Jobs } \\
\hline & SCST & OBC & Total \\
\hline Eduquota & 92.31 & 7.69 & 100 \\
\hline Jobquota & 79.31 & 20.69 & 100 \\
\hline Any quota & 88.6 & 11.4 & 100 \\
\hline
\end{tabular}

Table 3 (Part A) shows that a greater proportion of SCSTs (44 per cent), compared with OBCs (around 8 per cent), used reservation at least once in their lives. Of those who used reservations, 89 percent were SCSTs, and 11 percent were OBCs. Part B of Table 3 shows that of those who used reservation in education, the overwhelming proportion (92 per cent) consisted of SCSTs. The lower use of educational quotas by OBCs needs to be understood in the specific context of these respondents. These respondents were in undergraduate programmes during years when education quotas had not been extended to OBCs. In their verbal responses, several OBC respondents said that they would have used reservations if they had the opportunity to do so.

Prior to assessing how many opted to use quotas for job, we first need to see how many worked in 
government jobs, where quotas are applicable. Only 13 percent of those eligible for quotas worked in government jobs (15 percent of SC-STs and 10.5 percent of OBCs). Thus, the overwhelming majority of the young men in the sample were working in the private sector where quotas are not applicable. Of those who were working in government jobs, 37 percent used job quotas, with 43 percent of SCSTs and 22 percent of OBCs using job quotas.

We should note a caveat here, which could be a potential source of selection bias. This division between government and private jobs is for those individuals who already have jobs. Thus, it is not clear whether those who opted for private jobs did so because of lack of supply of government jobs or because they did not want to use quotas. However, it is also true that those who want government jobs but do not wish to enter through the quota route can do so by not revealing their caste category in the application process.

\subsection{Users versus Non-Users}

Let us call those who have used AA at least once 'users' and those who have never used AA 'nonusers'. The stream chosen by respondents in their higher secondary years is significantly correlated with use of quotas. Of those who are users, 52 percent are those who opted for arts/humanities in Class XII, 20 percent studied commerce, 12 percent are those who opted for science without biology (the engineering stream) and 16 percent are those who opted for science with biology.

Overall, 56 per cent users were first-generation beneficiaries; that is, no one in their families from earlier generations had used quotas. Here the difference between SC-STs and OBCs is stark, reflecting the longer period for which SC-ST quotas have been in application. Of the SC-STs who used quotas, 54 percent were first generation beneficiaries, with the corresponding proportion for OBCs being 80 . What is noteworthy is that despite such a long history, over half the SCST users were first generation beneficiaries.

Testing for differences in various socio-economic characteristics of users and non-users, we find that on most background characteristics, users have higher socio-economic characteristics than non-users. Average years of education of users' fathers is higher than that for non-users. Both fathers' occupation (in the 1-digit National Classification of Occupations scale, with 1 being the highest ranked occupation) and asset index are higher for users than for non-users.

Tables 4 and 5 show that differences between users and non-users in a variety of socio-economic indicators. The two statistically significant differences are in Class XII scores and years of education. Users having a higher average score (57 per cent) than non-users (54 per cent) and higher average years of education (16 years, compared to non-users' 15 years). This is to be expected because those with higher scores are more likely to study further and/or apply for government jobs where they might need to use reservations. This could be either due to the fact that those who score higher marks are more motivated, and/or that their probability of getting admission into college is higher. Additionally, we should note that the more "meritorious", judged by the narrow criterion of Class XII scores are the ones who actually use quotas. 
Table 4: Summary Statistics: Non-Users

\begin{tabular}{lccccc}
\hline \multicolumn{1}{c}{ Variable } & Mean & Std. Dev. & Min. & Max. & N \\
\hline age & 28.71 & 1.461 & 25 & 35 & 307 \\
xii_score & 54.655 & 9.316 & 33 & 80 & 305 \\
eduyrs & 14.86 & 1.778 & 12 & 20 & 307 \\
assetclass & 1.608 & 0.695 & 1 & 3 & 288 \\
fatheduyrs & 9.072 & 4.709 & 0 & 20 & 304 \\
fath_occ1dig & 5.647 & 1.979 & 1 & 9 & 303 \\
motheduyrs & 3.721 & 4.477 & 0 & 16 & 305 \\
\hline
\end{tabular}

Table 5: Summary Statistics: Users

\begin{tabular}{lccccc}
\hline \hline \multicolumn{1}{c}{ Variable } & Mean & Std. Dev. & Min. & Max. & N \\
\hline age & 28.669 & 1.48 & 25 & 33 & 118 \\
xii_score & 57.12 & 9.945 & 38 & 88 & 118 \\
eduyrs & 15.475 & 1.562 & 12 & 21 & 118 \\
assetclass & 1.706 & 0.643 & 1 & 3 & 109 \\
fatheduyrs & 9.907 & 5.047 & 0 & 20 & 118 \\
fath_occ1dig & 5.553 & 2.23 & 1 & 9 & 114 \\
motheduyrs & 3.353 & 4.179 & 0 & 12 & 116 \\
\hline
\end{tabular}

Those who do not study further, if interested in government jobs, would tend to apply for jobs that are at the bottom of the hierarchy. Several of these jobs, for instance, especially positions of cleaners, have an over-representation of SCSTs such that their proportion is much higher than the mandated quotas. Thus, access to such jobs is not facilitated through quotas. This is because in India, cleaning is the traditional occupation of a highly stigmatized caste that is considered untouchable. ${ }^{9}$ If stigma were to be a reason to discourage the uptake of AA, then it should matter more to the better-off families; however, prima facie, that does not seem to be the case in our data.

\subsection{What Factors Explain Use of Quotas?}

We now investigate what factors account for the use of quotas. Running a logistic regression based on Equation 4, we first estimate the odds-ratios for use of AA for OBCs relative to SC-STs, controlling for Class XII scores and father's education, with robust standard errors, clustered at the school level. The estimates reveal that OBCs in this sample are significantly less likely to use reservations compared to SC-STs for every level of Class XII scores at average levels of father's education. For SC-STs the probability of quotause increases monotonically with an increase in Class XII scores. However, for OBCs, an increase in scores beyond $76 \%$ reduces the probability of using quotas to close to zero. Recall that in this particular sample, OBC men were not entitled to education quotas

\footnotetext{
${ }^{9}$ See Deshpande and Weisskopf (2014) for a discussion of this issue.
} 
when they were students. This could be one reason explaining the lower use of quotas. Figure 1 shows the probability of use of quotas for the two groups, along with a $95 \%$ confidence interval.

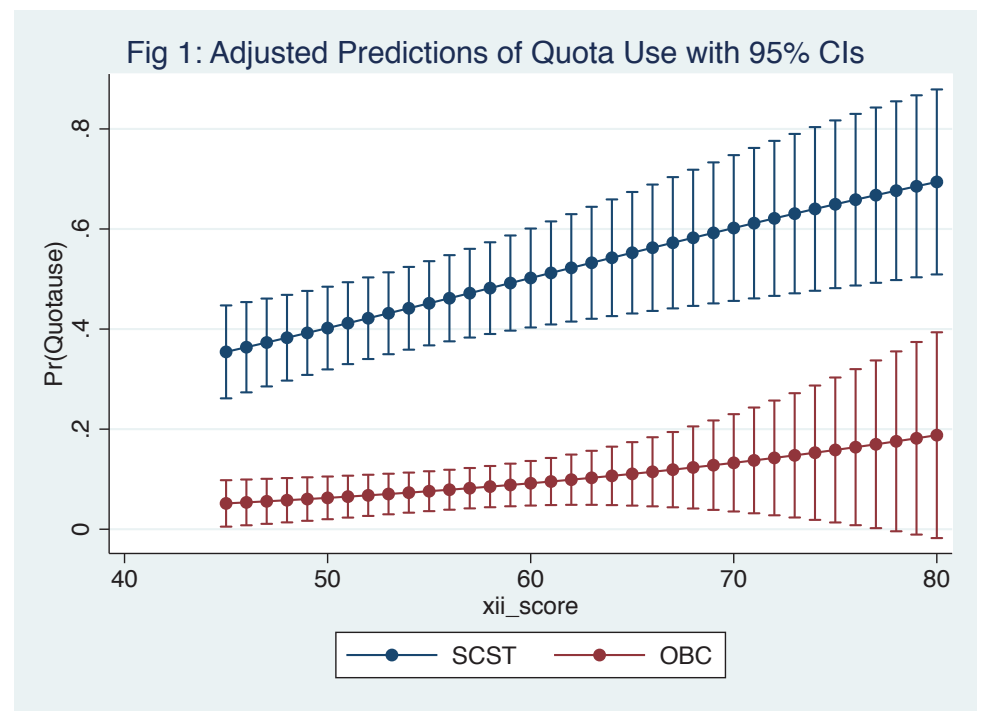

We now run the same regression adding another control for assetclass, as a proxy for family background. Figure 2 show the probability of the two eligible groups - SC-ST and OBCs - using quotas separately by asset class for each level of Class XII score, at average levels of father's education. As earlier, the $95 \%$ confidence intervals are estimated with robust standard errors, clustered at the school level. The graph for the poorest households (assetclass=1) shows that for SC-STs in this class, the probability of quota use increases monotonically with Class XII scores, whereas for OBCs belonging to this class, the probability of quota use turns positive for those who score more than $65 \%$, i.e. the high-scoring individuals. Within the middle-class households (assetclass=2), OBCs are not likely to use quotas, whereas for SC-STs the pattern is similar to their poor counterparts, except the increase in probability with Class XII score is less sharp. OBCs in the richest class (assetclass=3) are not likely to use quotas at all, and for SC-STs, the probability of use goes to zero as their score crosses $67 \%$. This could be because the better performing Dalit students reveal a high level of internal motivation and are likely to get in without the use of quotas.

Examining probability of use separately for the three asset classes reveals nuances in the process. The poorest SC-STs are most likely to use it, and the richest OBCs least likely. This result is consistent with Gille's (2013) result that richer OBCs are least likely to use quotas, maybe because they do not need to use them. Given the objective of affirmative action, viz., to enable entry for those who are not likely to make it on their own, this pattern suggests that those who need it the most are indeed the most likely to use it. This is further explored in Section 3.5 below. 


\section{Fig 2: Adjusted Predictions of Quota Use by Asset Class}

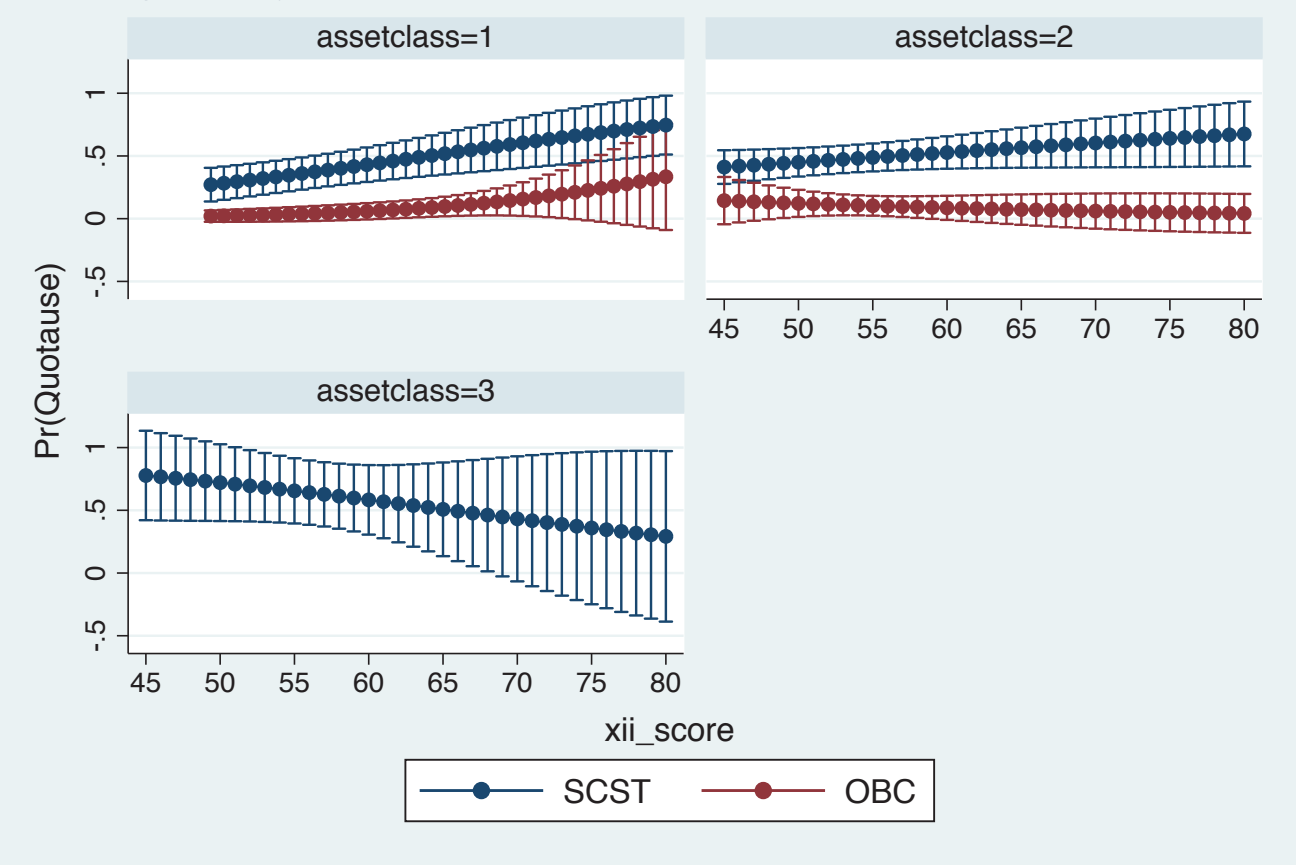

\subsection{Reasons for Not Using AA}

Those who did not use reservations even once were asked about the reasons behind their decision and were given six options to choose from: (1) not eligible (those who did not have the minimum marks for applying, even with the lower eligibility for reserved category candidates, or OBCs who were not eligible at the time as they were students at a time when there were no quotas for OBCs); (2) to show one could do without government help; (3) did not want added stigma of reservation (i.e. of being in the 'reserved category'); (4) did not know about the scheme (information constraints); (5) no occasion to use it (e.g. if the respondent went to a private institution after class XII, or were in private employment); and (6) bureaucratic difficulties. Of these, (3) is a direct indicator of 'additional stigma of reservations'. Reason no. 2 is more an indicator of self-confidence or high self-esteem, reflecting a positive attitude, but it could also indicate the desire to not be stigmatized as quota beneficiaries. Those who chose option (6) were further asked to verbalize the kinds of difficulties they faced. The reasons given were illuminating and offer insights into the administrative difficulties into accessing reservations. These include factors such as 'the process is complicated' and/or 'the documentation required is tough'; caste certificates from the village/district centre were not accepted in Delhi, and individuals were asked to make fresh certificates in the city; corruption (several reported that they were asked to give bribes); and explanations such as 'tried to use reservations on an earlier occasion, did not make it, hence did not try to use them again'.

Figure 3 shows the frequency responses from non-users across SC-STs and OBCs. 


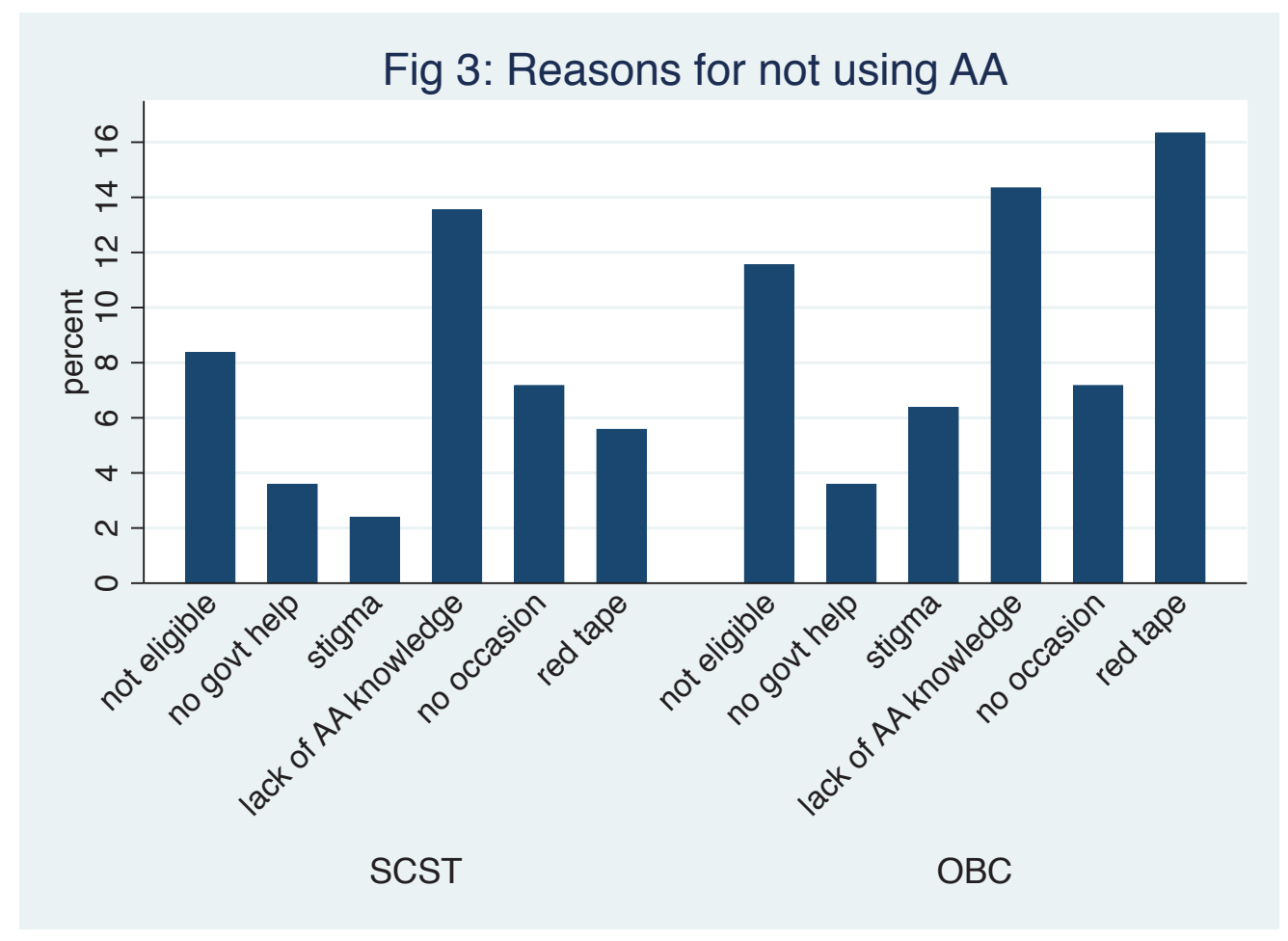

About $9 \%$ of non-users cite additional stigma (reason 2) as the reason for them not using reservations, and $16 \%$ if both reasons 2 and 3 are included as "stigma". For SC-ST, this proportion citing reason 2 is roughly 2 and for OBCs it is roughly 7 . Thus, for individuals who are from groups that are already highly stigmatized, the additional stigma of reservations is not a very important concern. For OBCs, the single largest reason is bureaucratic difficulties. The proportion of non-users claiming they did not know about it is consistent with the figures on first-time use of reservations, and surprising given the long history of reservations.

To understand the socio-economic factors underlying reasons for not using reservations, we estimate the multinomial logit regression, as explained in Section 3.1.2 with controls for asset class and caste group. As earlier, estimates are with robust standard errors clustered at the school level. Figure 4 shows the predicted probabilities for each reason, separately for SC-STs and OBCs for each of the three asset classes.

For SC-STs, the probability of stigma as the reason for non-use is positive but small for the poorest asset class, but reduces to zero for middle and rich asset classes. However, the positive sentiment of "don't need government help" sharply rises with asset class. For OBCs, 'not eligible', 'didn't know' and 'red tape' are more likely reasons than stigma. The probability of using stigma as a reason increases sharply across asset class for OBCs. It is useful to remind ourselves that OBCs do not face stigma similar to Dalits, and thus, it is not surprising to see that the richer OBCs are more likely to cite stigma as a reason, as these are individuals who would not otherwise be stigmatized. 
Fig 4: Adjusted Predictions of Reaons for Non-Use by Asset Class

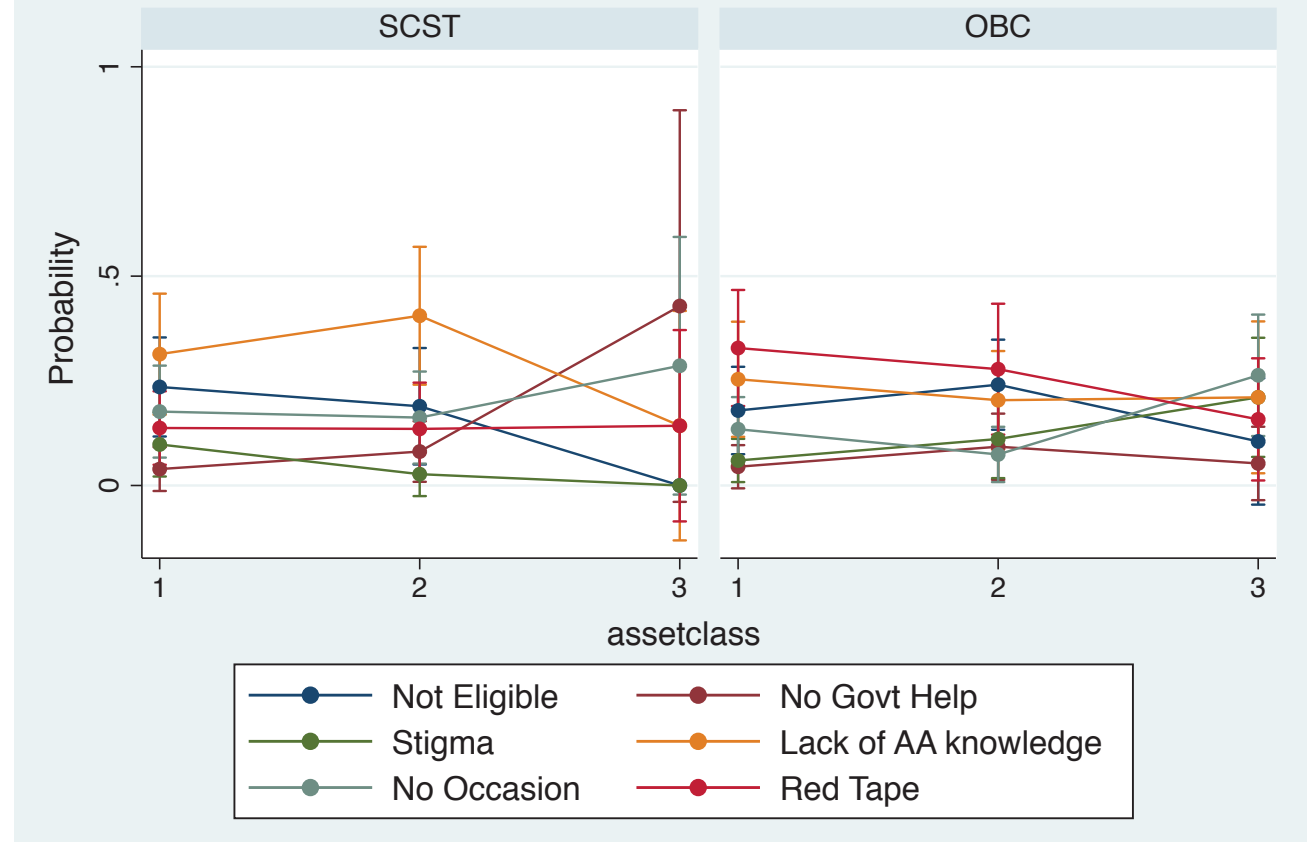

Thus, there are other important reasons that contribute to non-use, and focusing on stigma would not only be a misreading of the causes, but would also take attention away from important administrative/bureaucratic reasons that hamper eligible candidates from using AA. The basic result from the present study is that stigma is not the primary reason for the non-use of quotas. Or to put it differently, the perceived costs associated with stigmatization are not as high as the perceived benefits from using affirmative action.

\section{Experiences of Successful Quota Students}

What about the experiences of those who actually enter institutions using affirmative action? To what extent is stigma a factor in their college years? This is very difficult to estimate quantitatively. In order to understand experiences of assimilation (or otherwise) of those who got into colleges on quota and successfully completed their degrees, I decided to conduct qualitative interviews with successful reservation beneficiaries. ${ }^{10}$

In a separate survey, sixty-one individuals were interviewed over a period of three months in 2015.

\footnotetext{
${ }^{10}$ After the data for this paper had been collected and the first draft completed, the tragic suicide, in January 2016, of Rohit Vemula, a Dalit Ph.d. scholar at the University of Hyderabad, brought issues of stigmatization, assimilation, discrimination and harrassment sharply to the fore in the public discourse. I have dealt with some of those issues in Deshpande (2016).
} 
These were mostly personal contacts of my students. The sample is not representative, and not amenable to rigorous statistical analysis, but because the respondents were known to my students, who themselves are upper middle-class and therefore relatively advantaged, the experiences reported here are likely to be from the better off among beneficiaries. If they faced actual discrimination or even battled with the perception of discrimination, then it is reasonable to conclude that those who deal with multiple disadvantages, e.g. class or gender along with a caste stigma, would face more serious issues related to assimilation. In any case, the idea was to listen to some voices in order to get greater insight into the experiences of quota beneficiaries, after they enter the institution, i.e. after the formal completion of the policy: do beneficiaries experience assimilation or rejection? As we will see in what follows, this short selection of stories contains multiple layers, in the sense that there are multiple reasons why individuals might feel marginalised, and does not reveal a straightforward narrative confirming the double stigma of affirmative action.

\subsection{The Multiple Layers of Stigma}

Several of the respondents reported not facing any discrimination on account of their quota status. M10, who got a Ph.D and now works as an assistant professor, belongs to one of the most stigmatized jatis, Chamar. His father was a government employee, thus he is a second-generation beneficiary. His experience of being a student and employee is marked by his stigmatized ethnic identity, and he wishes he were born into another caste, as his life would have been much better. However, the stigma seems to emanate from his caste identity, rather than the fact that he used reservations. He believes "upper castes retaliate, with violence if necessary, if Dalits dress better than them or get more marks". M16, who is from the same caste, did not feel particularly stigmatized. He had several upper caste friends in university and found his teachers "very helpful". Similarly, Y61 did not feel discriminated while he was a student, and supports reservations, but feels that we need to move to a situation where reservations become unnecessary. M4, from the Julaha caste, felt stigmatized due to his caste, not necessarily to his quota status.

P11 felt discriminated against, and was not able to assimilate because of his shy nature. He feels reservations should be based on an income criterion, not caste, as that reinforces the feeling that lower-caste students are "inferior". P5 reported that lower-caste students tended to mingle with each other and did not easily mix with others. P10 reported that one of his teachers would "distribute marks" through a list that had the reserved category status written against the names of beneficiary students, and he felt that this was discriminatory.

P6, from the Jatav caste, did not use a quota despite being eligible as felt he could make it on his own. However, when he was on the job market, he felt that he was not equipped to compete as his "skill set" was not sufficient. He felt university education did not provide students with the capital needed to compete well in the employment world. It is not clear to what extent he holds his background responsible for his inadequacy in meeting the demands of the job market. M9 claims that he did not face any stigma in college, despite joining through quota, but does feel stigmatized in his workplace, as his colleagues know that he is a quota employee. M7 and M9 stressed the importance of networks for reserved category students. 


\subsubsection{Intersecting Identities}

M13, who is a tribal individual from the North-East, felt that he was at the receiving end of racial discrimination, confirming the accounts of racial stigma and violence directed towards those from the North-Eastern states, living in other parts of India. He also added that he might have been spared serious discrimination, as he is from a relatively better-off family. Y3 also faced taunts on account of his north-eastern identity. M15 is visually impaired, as well as OBC. He felt stigmatized due to the "excessive sympathy" that he received. His testimony brings to the fore the urgent need towards sensitization of peers regarding the appropriate behavior towards people with disability.

M1 and M11 who are Muslim, used quotas only for admission to M.A., not for prior education. They didn't feel the need to use it earlier. Their overall experience is positive and they felt that reservation helped him get that additional degree. M12, also a Muslim, did feel discriminated against on account of his religion and cited a situation where his teacher made him "uncomfortable in the classroom by asking questions about his religion". M10 came to Delhi from a small town. He did not feel any bias in Delhi but did feel stigmatized on account of his caste in his hometown. He feels that these distinctions might be weaker in the metropolitan cities compared to small towns.

\subsubsection{Accumulated Handicaps}

Several students, like Y47, Y43, Y51, P11, felt that lack of fluency in English was a handicap that most reserved category students had to battle with. M14, who has not yet started to work, felt that linguistic barriers kept him from integrating fully into the mainstream. He did not feel any overt caste-based discrimination or any additional stigma of being a reserved category student. Y43 felt severely disadvantaged due to the type of schooling he received, which after coming to university, he realized was markedly inferior to that of his upper-caste peers. Y42 echoes the weak schooling argument. P5 was a first-generation "learner", and felt handicapped due to the fact that he had a lot to catch up with. M18 felt that the lack of fluency in English was a major obstacle for reserved category students. He felt that his "bias is inherent in the attitudes of teachers as well. They treat them [reserved category students] condescendingly if they could not speak/write correct English ... quota students work very hard but end up scoring less than general category students".

Y60, a Jatav, had two contrasting experiences in his undergraduate and postgraduate institutions. In the former, he faced ragging and bullying. He points out that "category students" were demarcated and often upper-caste students refused to share rooms with them to avoid being polluted. He pointed out that the admission forms for the hostel were in a different colour for the "category students", and this might have heightened caste consciousness. He did not face any such segregation in his master's classes. 


\subsubsection{The Time and Class Dimension}

Y45 felt that discussions about quota are especially agitated in the first couple of months after university opens, but then students get on with the curriculum and admission related issues take a back seat. Y38 felt alienated in the first year, but settled down in the second year and felt more assimilated in the second year. Both accounts seem to suggest that discrimination lessens with time spent in college.

One respondent brought out the issue of class within caste, or the 'creamy layer'. M2 felt that "upper" [class] Dalits discriminated against "lower" [class] Dalits and first generation beneficiaries. He felt that this differentiation within reserved category students was important and some Dalits would act patronizingly towards other Dalits.

\subsubsection{Female Voices}

Most of the individuals who were interviewed were male, which reflects the unfortunate reality that beneficiaries of reservation tend to be disproportionately male. However, we were able to interview some women. Ten of the 61 respondents were female. Y57 felt stigmatized even though she was OBC (and not Dalit). She feels that stigmatizing attitudes are very common and that peers need to be sensitized towards reservations. She supports reservations wholeheartedly and asks "inequality is going up and general category students are rising, so why should the backward students not be a given a chance to rise?" Y56, from the Kushwaha caste (an OBC caste), felt severely disadvantaged, as her mother is illiterate, and even though she was motivated, there was nobody in her house who could help her study. She feels that it is difficult for reserved category students to adjust to the competitive life in the university. She is from Rajasthan, where everyone would ask her about what her father did and she felt that was to identify her caste. P2 did not feel any discrimination inside institutions but did not want to reveal her caste to anyone. She also pointed out that her teachers were all "elite", and wondered if there had been nepotism in hiring them.

\subsection{Stigmatising Attitudes of Employees and Others}

Y21 started out his college life very defensive about his caste identity and more importantly his reservation status. He avoided conversations with peers because inevitably those would start with a discussion about his marks, and he was afraid that by revealing his low marks, he would out himself as a reserved category student. However, as time passed, his fears eased and he found himself assimilating into college life by making new friends. His overall experience was positive, but he feels that "general category students don't understand the situation of "category" students".

Y57, from the Sonar caste, got a prestigious scholarship after his entry into the college, for which he was chosen through open competition being interviewed along with his peers. However, when he went to collect it, the administrative employee taunted him by suggesting that he got the scholarship because of a quota. He felt that such attitudes are very common. He feels his life would have turned out much better had he belonged to another (higher) caste. Y52, from the Chamar caste, 
himself never had any adverse experience in the university, but still feels that that life might have been much better had he been born into another (higher) caste. Y49 also reported facing taunts from the office staff in her department who referred to her 'quota status'.

Y56 reports a story about her brother who was studying hard to prepare for university entrance but used to be repeatedly told that he need not bother; he would get in anyway due to quota. M17, from the Jatav caste (who declared himself to be an atheist), did not feel discrimination in college (where he had been admitted through quota), but did feel it in school. He claimed that his name had been left out from the hall of fame in his school because of his caste, despite the fact that he was a topper. Once his teacher refused to sign his scholarship letter, and he was often told that he should just sit for civil services where he will get in easily because of his quota status.

\section{Discussion and Concluding Comments}

The reservation policy in India is a system of compensatory discrimination towards castes and communities that have been stigmatized and oppressed for centuries. The system is designed to counter exclusion that would come on account of prejudice, and allow entry to disadvantaged individuals to level the playing field in some spheres. However, due to Dalits' "stigmatized ethnic identity", the policy of affirmative action is seen as unjust and anti-merit, as one of the dimensions of stigmatization is the assumption of incompetence.

This paper investigates the issue of additional stigma of reservations through a mixed-methods research design. The quantitative estimates based on a primary survey in the city of Delhi indicate that use of reservation is not adversely affected due to fear of stigmatisation. Red tape and bureaucratic hurdles, indicative of administrative apathy towards the policy, are far bigger constraints in the use of reservations than the fear of stigma. Overall, while stigma is one of the reasons underlying the non-use of reservations, it is not the primary reason. Also, for the already stigmatized Dalit and Adivasi individuals, it is a very small reason. It is a greater factor for the relatively rich students within the sample, than the poorer, and also a greater factor for OBCs, who do not suffer the stigma of untouchability, compared to the already stigmatized Dalits.

Instituting quotas is a way of ensuring access to higher education and good jobs. However, that is only the starting point; the test of the success of affirmative action lies in how well beneficiaries are able to integrate within institutions into which they gain entry. Rohit Vemula's tragic suicide in early 2016 has brought the issue of assimilation, alienation and discrimination to the fore. Experiences of discrimination are unpleasant, and possibly traumatic and painful. It is likely that short interviews such as the ones reported in this paper might not be able to capture the whole experience or get respondents to fully open up. Also, these are students who successfully completed their degree, which means that the combination of circumstances - their university experience, their own ability, internal motivation and effort - worked to enable their success. This combination would be much more adverse for those who drop out. 
Nevertheless, these interviews are useful and reveal, one that even for the successful reserved category students, integration into colleges and university departments is not without challenges, but two, that success is possible, thus affirmative action is not a lost cause. Most of the interviewees were supportive of reservations, and felt that they would not have been able to achieve what they did without it. This resonates with the findings of Bowen and Bok's (1998) seminal study of the long-term consequences of affirmative action in the US. Some, like P32 and P2, wanted reservations to be extended to the private sector. However there were dissenting voices, who either advocated an income criterion or no reservation at all, despite themselves being beneficiaries of caste-based reservations.

The running thread in the interviews is the repeated reference to their caste, which indicates that even in contexts where affirmative action is not applicable, there is likely to be stigma arising on account of caste. Several respondents highlighted the disadvantages due to their relatively weaker pre-college background in terms of quality schooling, lack of fluency in English, lack of adequate academic support at home and so forth. Accounts also pointed out discrimination in schools, and drew attention to a troubling tendency on the part of teachers and peers to actively thwart aspirations by discouraging lower-caste students from aiming high or pursuing their dreams. Several were told to just try for government jobs where they would get in easily on a quota, which the respondents found hurtful and insulting.

Access to quotas altered the respondents' life chances for the better. In the long run, I believe that these success stories will help weaken the stigmatizing association between low-caste status, and incompetence. However, the multiplicity of challenges that beneficiaries faced indicates that affirmative action in the form of quotas is not a magic wand solution to the multi-faceted problem of discrimination, and can only be one, albeit extremely crucial, link in a chain of policies that need to be designed to battle caste disadvantage.

\section{References}

Berreman, Gerald D. 1971. Self, Situation and Escape from Stigmatised Ethnic Identity, Paper presented at the 70th Annual Meeting of the American Anthrological Association, available at http://eric.ed.gov/?id=ED058344, accessed November 2016.

Bagde, S., D. Epple, and L. Taylor. 2016. "Does Affirmative Action Work? Caste, Gender, College quality, and Academic Success in India", American Economic Review, 106(6), 1495-1521.

Bertrand, M., R. Hanna, and S. Mullainathan (2010). "Affirmative Action in Education: Evidence from Engineering College Admissions in India", Journal of Public Economics, 94(1-2): 16-29.

Deshpande, A. (2013). Affirmative Action in India, Oxford India Short Introduction Series, Oxford University Press, New Delhi.

Deshpande, A., and T.E. Weisskopf (2014). "Does Affirmative Action Reduce Productivity? A Case Study of the Indian Railways". World Development, 64(December): 169-80. 
Deshpande, A. (2016). "Double Jeopardy? Caste, Affirmative Action and Stigma", UNU-WIDER Working Paper, 2016/71, Helsinki.

Fiske, S.T., A.J. Cuddy, P. Glick, and J. Xu (2002). "A Model of (Often Mixed) Stereotype Content: Competence and Warmth Respectively Follow from Perceived Status and Competition". Journal of Personality and Social Psychology, 82(6): 878-902.

Gille, V. (2013). Stigma in Affirmative Action Application? Evidence from Quotas in India. Mimeo.

Gudavarthy, A. (2012). "Can We De-Stigmatise Reservations in India?", Economic and Political Weekly, 47(6): 55-62.

Guru, G. (ed.) (2009). Humiliation: Claims and Context, Oxford India Paperbacks Series, New Delhi: Oxford University Press.

Leslie, L.M., D.M. Mayer, and D.A. Kravitz (2014). "The Stigma of Affirmative Action: A Stereotyping-Based Theory and Meta-analytic Test of the Consequences for Performance", Academic of Management Journal, 57(4): 964-89.

Navsarjan Trust (2010): Understanding Untouchability: a comprehensive study of practices and conditions in 1589 villages, Robert F. Kennedy Centre for Justice and Human Rights and Navsarjan Trust, Ahmedabad.

Shah, Ghanshyam, Harsh Mandar, Sukhadeo Thorat, Satish Deshpande, and Amita Baviskar (2006), Untouchability in Rural India, New Delhi: Sage Publications.

Sharma, Smriti (2015). "Caste-Based Crimes and Economic Status: Evidence from India", Journal of Comparative Economics, 43(1): 204-26.

Thorat, A. and O. Joshi (2015). The continuing practice of untouchability in India: Patterns and mitigating influences, India Human Development Study Working Paper 3. 